\title{
Pozolanas de elevada reatividade: uma avaliação crítica do ensaio de Índice de Atividade Pozolânica (IAP) com cal usando Difração de Raios X
}

\author{
High reactivity pozzolan: a critical evaluation of \\ Pozzolanic Activity Index (PAI) with lime using X-Ray \\ Diffraction
}

\begin{tabular}{|c|c|}
\hline & $\begin{array}{l}\text { Marcelo Henrique Farias de Medeiros } \\
\text { Juarez Hoppe Filho } \\
\text { Andressa Gobbi } \\
\text { Eduardo Pereira }\end{array}$ \\
\hline & Res \\
\hline & 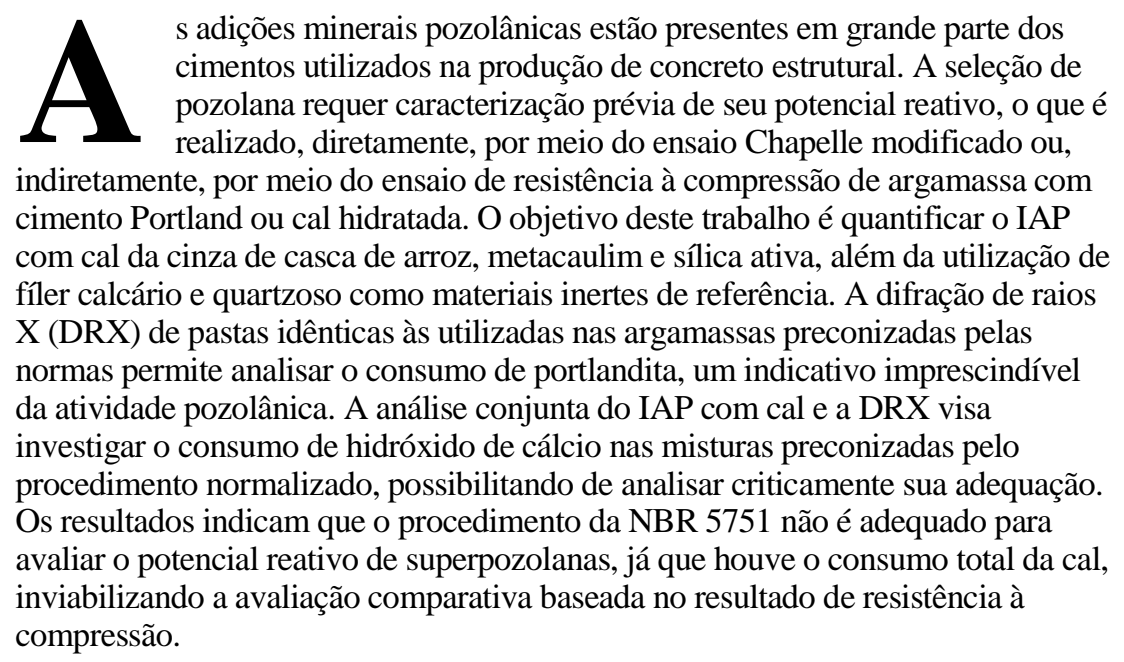 \\
\hline & Palavras-chaves: Adições minerais. Atividade pozolânica. Resistência à compressão. \\
\hline & Abstract \\
\hline $\begin{array}{r}\text { Marcelo Henrique Farias de } \\
\text { Medeiros } \\
\text { Universidade Federal do Paraná } \\
\text { Curitiba - PR - Brasil }\end{array}$ & $\begin{array}{l}\text { Mineral pozzolanic admixtures are present in many of cementitious materials } \\
\text { used in the production of structural concrete. The selection of the pozzolan } \\
\text { requires prior characterization of its reactive potential, which can be obtained } \\
\text { directly by using the modified Chapelle test, or indirectly, by performing a } \\
\text { compressive strength test of the mortar with Portland cement or hydrated }\end{array}$ \\
\hline $\begin{array}{r}\text { Juarez Hoppe Filho } \\
\text { Universidade Federal do Oeste da } \\
\text { Bahia } \\
\text { Barreiras - BA - Brasil }\end{array}$ & $\begin{array}{l}\text { lime. The objective of this study is to quantify the pozzolanic activity index } \\
\text { with lime of rice husk ash, silica fume and metakaolin, as well as the use of } \\
\text { fillers such as limestone and quartz dust as inert reference material. The X-ray } \\
\text { diffraction (XRD) of pastes identical to those used in standard mortars allows }\end{array}$ \\
\hline $\begin{array}{r}\text { Andressa Gobbi } \\
\text { Universidade Federal do Paraná } \\
\text { Curitiba - PR - Brasil }\end{array}$ & $\begin{array}{l}\text { us to analyse portlandite consumption, an essential indicative of pozzolanic } \\
\text { activity. The combined analysis of IAP with lime and X-ray diffraction (XRD) } \\
\text { is aimed at verifying the rate of consumption of calcium hydroxide in the } \\
\text { mixtures recommended by standard procedures, creating an opportunity to }\end{array}$ \\
\hline $\begin{array}{r}\text { Eduardo Pereira } \\
\text { Universidade Estadual de Ponta } \\
\text { Grossa } \\
\text { Ponta Grossa - PR - Brasil }\end{array}$ & $\begin{array}{l}\text { critically analyse their suitability. The results indicate that the NBR } 5751 \\
\text { procedure is not appropriate to compare the reactive potential of super } \\
\text { pozzolan, since the investigation showed that the amount of lime in the mixture } \\
\text { was completely consumed, preventing a comparative evaluation of the }\end{array}$ \\
\hline $7 / 14$ & compressive strength results based on standardized testing. \\
\hline & Keywords: Mineral admixtures. Pozzolanic activity. Compressive strength. \\
\hline
\end{tabular}

MEDEIROS, M. H. F. de; HOPPE FILHO, J.; GOBBI, A.; PEREIRA, E. Pozolanas de elevada reatividade: uma avaliação crítica do ensaio de Índice de Atividade Pozolânica (IAP) com cal usando Difração de Raios X. Ambiente Construído, Porto Alegre,v. 15, n. 3, p. 19-29, jul./set. 2015.

ISSN 1678-8621 Associação Nacional de Tecnologia do Ambiente Construído. http://dx.doi.org/10.1590/s1678-86212015000300023 


\section{Introdução}

As adições minerais pozolânicas podem ser incorporadas ao cimento Portland durante o processo de fabricação do material ou utilizado como adição in loco para a execução de concretos e argamassas. A incorporação de adições minerais à composição do cimento propicia vantagens econômicas e ambientais, além de interferir na microestrutura da matriz hidratada, incrementando, na maioria das vezes, a durabilidade das obras executadas com esse material ligante. De acordo com Mehta e Monteiro (2014), as adições minerais são acrescentadas em quantidades relativamente grandes, entre $20 \%$ e $70 \%$ da massa do material cimentício total, adicionando ou substituindo parcialmente o cimento, dependendo das propriedades que se quer obter.

Os estudos na área de pozolanas têm abordado temas como o alto teor de substituição, como nos trabalhos de Hoppe Filho et al. (2013), Isaia e Gastaldini (2009) e Hoppe Filho (2002); o uso de composições com mais de uma adição (ISAIA, 1995; ISAIA; FURQUIM; GASTALDINI, 2012); a produção a partir de cinzas provenientes da queima de resíduos agroindustriais, como é o caso da cinza de bagaço de cana-de-açúcar, abordado por Cordeiro et al. (2008), Gobbi, Groenwold e Medeiros (2010) e Frias, Villar Cociña e Savastano Junior (2011), o caso da cinza de folha de bananeira, como no trabalho de Kanning et al. (2014), o caso da cinza de folha de bambu, pesquisada por Villar-Cociña et al. (2011), e o caso das cinzas de casca de arroz, como estudado por Zerbino, Giaccio e Isaia (2011); e a investigação da temperatura e tempo de calcinação de argilas para produção de pozolanas artificiais a serem utilizadas em substituição parcial do cimento, em diferentes teores, conforme Chakchouk et al. (2009), que mostrou que as propriedades mecânicas foram regidas pela temperatura de calcinação e teor de substituição, sendo possível aumentar os teores de substituição desde que a temperatura de calcinação seja elevada.

Além de aspectos referentes aos tipos de pozolanas e fatores relativos à produção e teor de adições minerais, os efeitos da atividade pozolânica na durabilidade do concreto em meios agressivos são abordados em diversos trabalhos, tais como Medeiros et al. (2014), os quais desenvolveram um estudo focado em ambiente marinho; Heede e Belie (2014) e Marques, Chastre e Nunes (2013), focados no estudo sobre a resistência à carbonatação; Lee et al. (2011) e Zerbino et al. (2012), que estudaram o efeito das pozolanas na capacidade de mitigação da RAA; Hodhod e
Salama (2013) e Hoppe Filho et al. (2014), que focaram seus estudos na durabilidade com relação ao ataque por sulfatos; e Pacheco-Torgal e Jalali (2009), que pesquisaram o efeito das pozolanas na durabilidade em ambientes ácidos.

No Brasil, a caracterização das adições minerais ativas está baseada, na prática, em métodos diretos e métodos indiretos de quantificação do potencial reativo. São indiretos os ensaios que medem a pozolanicidade por meio do índice de atividade pozolânica (IAP) com cimento Portland ou cal hidratada, conforme preconizam as normas NBR 5752 (ABNT, 2012a) e 5751 (ABNT, 2012b) respectivamente. $\mathrm{O}$ método direto, denominado ensaio Chapelle modificado (ABNT, 2010), determina a capacidade da adição pozolânica em fixar cal para a formação de compostos hidratados, que, apesar de mais criterioso em comparação aos métodos indiretos, é de realização restrita a centros especializados, pois é um método de determinação química que envolve equipamentos e conhecimentos muito específicos da área.

Nesse contexto, Gava e Prudêncio Junior (2007) identificaram a possibilidade de alguns métodos indiretos resultarem em falso negativo, o que restringiria o uso de determinadas adições por não cumprirem os requisitos normativos, porém, na prática, tais adições apresentam desempenho reconhecidamente adequado como material pozolânico. Além disso, os autores criticam o fato de os métodos não considerarem a área específica da adição, o teor de substituição e a relação água/sólidos constante, o que faz com que pozolanas de grande área específica, mais reativas, apresentem desempenho minorizado em função da maior demanda de água de mistura. Donatello, Tyer e Cheeseman (2010) recomendam que, ao avaliar a atividade pozolânica de um material, é importante a escolha do método a ser utilizado, baseado em suas particularidades, isto é, conhecimento das limitações e das condições de ensaio. Assim sendo, recomendam a avaliação por mais de um método, apesar de que podem não apresentar correlação entre eles e de que pelo menos um deles deve apresentar uma tendência evolutiva de consumo de portlandita. Um desses detalhes de ensaio a ser definido e fixado é a temperatura de cura, uma vez que o estudo de Abd-El.Aziz, Abd.El.Aleem e Heikal (2012) demonstrou que o aumento da temperatura de cura propicia maior consumo de cal por atividade pozolânica, com redução no volume total de poros e incremento no comportamento mecânico das pastas. 
Apesar de suas limitações, os métodos normalizados pela ABNT de quantificação do potencial reativo são capazes de auxiliar na escolha das pozolanas normalmente utilizadas, porém podem subestimar a reatividade das superpozolanas, como a cinza de casca de arroz, a sílica ativa e o metacaulim. A alta reatividade dessas adições, decorrente do alto teor de amorfos e da grande área específica, conduz a um elevado consumo de portlandita, que, nas argamassas de cimento Portland ou cal hidratada preconizadas pelas respectivas normas brasileiras para determinar o IAP, pode esgotar a reserva alcalina do meio, sobretudo em condição de reação catalisada pela cura térmica. Assim sendo, o objetivo deste trabalho é verificar se as relações hidróxido de cálcio/pozolana, em massa, utilizadas no método indireto de avaliação do índice de atividade pozolânica (IAP) com cal, preconizado pela norma NBR 5751 (ABNT, 2012b), são adequadas para determinar o potencial reativo das pozolanas de alta reatividade.

\section{Materiais e métodos}

O desenvolvimento do programa experimental proposto foi baseado no ensaio para a determinação do índice de atividade pozolânica com cal, conforme a NBR 5751 (ABNT, 2012b), e no estudo em pasta, para a quantificação do consumo de cal por atividade pozolânica, por meio de difração de raios X. As adições minerais pozolânicas avaliadas foram sílica ativa, metacaulim e cinza de casca de arroz, além do fíler calcário e do fíler quartzoso, adições minerais inertes, utilizadas como referências de comparação com as adições pozolânicas. O agregado miúdo utilizado para os ensaios de IAP foi a areia normal brasileira (ABNT, 2012c), que contém 234 gramas de cada fração granulométrica.

\section{Materiais utilizados}

O cimento utilizado foi o CP V - ARI. As adições minerais ativas utilizadas foram a cinza de casca de arroz, a sílica ativa e o metacaulim, e como adições inertes o fíler calcário e o fíler quartzoso (pó de quartzo). A Tabela 1 apresenta a massa específica e as áreas específicas Blaine e BET das adições minerais. A análise química dos materiais foi realizada por fluorescência de raios $X$. Os resultados são apresentados na Tabela 2.

Os resultados de área específica BET são similares aos apresentados por Cervo (2001), em que o cimento CP V - ARI foi caracterizado com 1,8 $\mathrm{m}^{2} / \mathrm{g}$, a cinza de casca de arroz com $36,3 \mathrm{~m}^{2} / \mathrm{g}$, e a sílica ativa com $17,2 \mathrm{~m}^{2} / \mathrm{g}$. Barata e Angélica (2011) também obtiveram valores semelhantes (entre 7,9 e $16,8 \mathrm{~m}^{2} / \mathrm{g}$ ) estudando atividade pozolânica de resíduos cauliníticos.

Cordeiro et al. (2011), em estudo sobre a influência da finura da cinza de casca de arroz em sua atividade pozolânica, e também empregando o método Blaine e BET, não encontraram resultados da mesma ordem de grandeza pelos dois métodos, obtendo valores próximos a $34 \mathrm{~m}^{2} / \mathrm{g}$ pelo método BET e a $1,2 \mathrm{~m}^{2} / \mathrm{g}$ pelo método Blaine, o que corrobora os resultados referentes à cinza de casca de arroz apresentados na Tabela 1 .

Tabela 1 - Massa específica e área específica Blaine e BET das adições minerais

\begin{tabular}{l|l|c|c|c}
\hline \multicolumn{2}{c|}{$\begin{array}{c}\text { Adições minerais e cimento } \\
\text { Portland }\end{array}$} & $\begin{array}{c}\text { Massa específica } \\
\left(\mathbf{g} / \mathbf{c m}^{\mathbf{3}}\right)\end{array}$ & $\begin{array}{c}\text { Área específica } \\
\text { Blaine }\left(\mathbf{m}^{\mathbf{2}} \mathbf{g}\right)\end{array}$ & $\begin{array}{c}\text { Área superficial } \\
\text { BET }\left(\mathbf{m}^{\mathbf{2}} / \mathbf{g}\right)\end{array}$ \\
\hline Cimento & CP V - ARI & 3,13 & 0,451 & 1,071 \\
\hline \multirow{3}{*}{ Ativas } & Cinza de casca de arroz & 2,12 & 0,696 & 14,693 \\
& Sílica ativa & 2,18 & 0,718 & 20,238 \\
& Metacaulim & 2,50 & 0,474 & 23,259 \\
\hline \multirow{2}{*}{ Inertes } & Fíler calcário & 2,70 & 0,760 & 1,413 \\
& Fíler quartzoso & 2,60 & 0,795 & 1,227 \\
\hline
\end{tabular}

Tabela 2 - Composição química do cimento Portland e das adições minerais

\begin{tabular}{|c|c|c|c|c|c|c|c|c|c|c|c|}
\hline \multicolumn{12}{|c|}{ Composição química (\%) } \\
\hline Amostras & $\mathrm{SiO}_{2}$ & $\mathrm{~K}_{2} \mathrm{O}$ & $\mathrm{Fe}_{2} \mathrm{O}_{3}$ & $\mathrm{CaO}$ & $\mathbf{A l}_{2} \mathbf{O}_{3}$ & $\mathbf{P}_{2} \mathbf{O}_{5}$ & $\mathrm{TiO}_{2}$ & $\mathrm{SO}_{3}$ & MgO & $\begin{array}{l}\text { Outros } \\
\text { óxidos }^{*}\end{array}$ & $\begin{array}{c}\text { Perda ao } \\
\text { fogo }\end{array}$ \\
\hline Cimento CP V - ARI & 10,45 & 1,36 & 3,71 & 73,21 & 3,59 & - & 0,26 & 3,05 & 3,66 & 0,70 & 3,20 \\
\hline Fíler calcário & 1,76 & 0,36 & 0,52 & 84,16 & 1,15 & - & - & 0,62 & 11,07 & 0,36 & 45,20 \\
\hline Fíler quartzoso & 95,65 & - & - & - & 2,43 & - & 0,04 & 1,77 & - & 0,04 & 0,13 \\
\hline Cinza de casca de arroz & 88,94 & 4,18 & 0,11 & 1,10 & 2,42 & 0,24 & - & 2,08 & - & 0,93 & 3,00 \\
\hline Metacaulim & 45,86 & - & 3,90 & 0,14 & 46,05 & - & 2,22 & 1,69 & - & 0,05 & 6,60 \\
\hline Sílica ativa & 92,49 & 2,76 & 0,13 & 0,51 & 1,91 & - & - & 2,08 & - & 0,12 & 2,70 \\
\hline
\end{tabular}

Nota: "Outros óxidos: $\mathrm{ZnO}+\mathrm{MnO}+\mathrm{CuO}+\mathrm{Rb}_{2} \mathrm{O}+\mathrm{Tm}_{2} \mathrm{O}_{3}+\mathrm{SrO}$. 
O hidróxido de cálcio foi caracterizado por análise térmica (TG/DTG), usando o equipamento Mettler-Toledo Star SW 9.30. O reagente químico, conforme a Figura 1, contém aproximadamente $1,50 \%$ de água, que foi completamente volatilizada até $350{ }^{\circ} \mathrm{C}$, e $8,97 \%(3,95 \%$ x 2,27) de carbonato de cálcio. O hidróxido de cálcio representa $86,93 \%$ $(21,15 \%$ x 4,11) da massa do material.

\section{Índice de atividade pozolânica com cal, conforme a NBR 5751 (ABNT, $2012 \mathrm{~b}$ ), e consumo de portlandita em pastas por difração de raios $X$}

A determinação do IAP com cal, conforme preconiza a NBR 5751 (ABNT, 2012b), requer que as argamassas a serem submetidas ao ensaio de resistência à compressão apresentem no estado fresco índice de consistência preestabelecido (225 $\mathrm{mm} \pm 5 \mathrm{~mm}$ ), o que conduz a variados volumes de água de mistura em função das características físico-químicas das adições minerais estudadas. A
Tabela 3 apresenta as proporções de mistura das argamassas em massa para os diferentes tipos de adições minerais e a relação portlandita/adição mineral de cada argamassa.

A técnica de difração de raios $\mathrm{X}$ foi usada para a identificação de teor remanescente de cal nas pastas após 7 dias de atividade pozolânica. Para tanto, foram moldadas amostras de pasta seguindo as recomendações da NBR 5751 (ABNT, 2012b), ou seja, o volume de adição mineral é o dobro do volume de hidróxido de cálcio. A relação água/sólidos foi mantida constante em 0,80 , de forma a permitir a adequada mistura das pastas com sílica ativa e metacaulim, as quais demandam maior volume de água em decorrência de suas características físico-químicas, verificadas na Tabela 1. Após a mistura, as pastas foram lançadas em sacos plásticos $( \pm 25 \mathrm{~mL})$ e acondicionadas em recipientes poliméricos de $50 \mathrm{~mL}$, com tampa, objetivando minimizar a evaporação da água na cura térmica, a $(55 \pm 2){ }^{\circ} \mathrm{C}$ durante 6 dias, após 1 dia de cura à temperatura de $(23 \pm 2)^{\circ} \mathrm{C}$.

Figura 1 - Análise termogravimétrica do hidróxido de cálcio p.a. utilizado

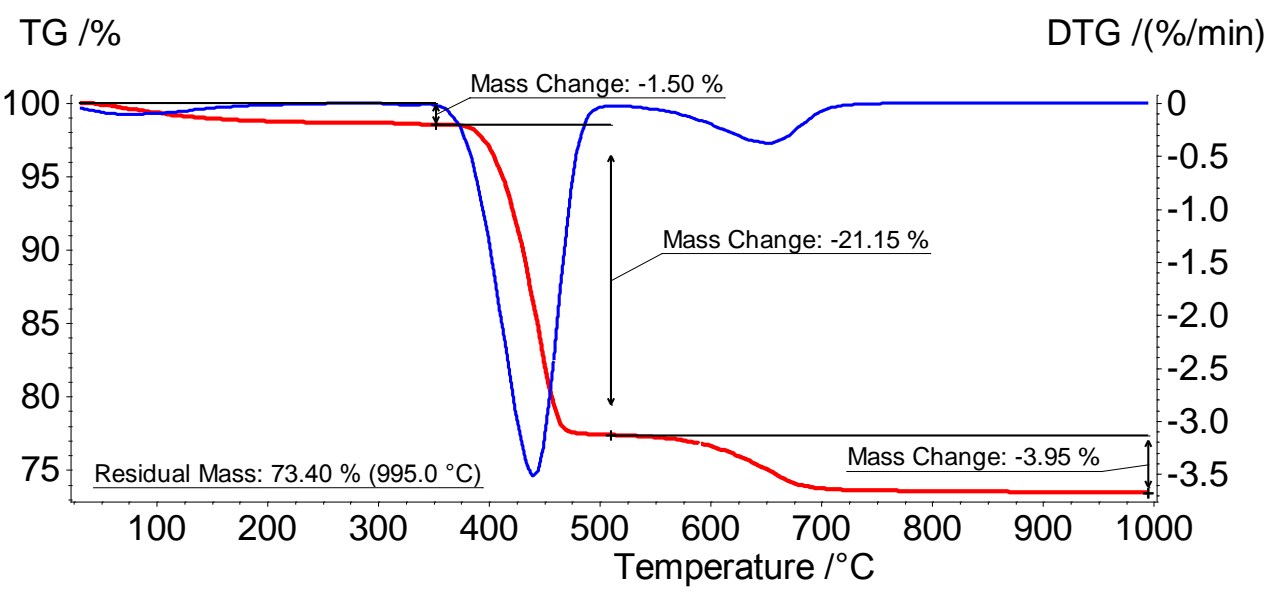

Tabela 3 - Proporção de mistura das argamassas, relação água/sólidos e relação hidróxido de cálcio/adição mineral

\begin{tabular}{|c|c|c|c|c|c|c|c|}
\hline & \multirow[b]{2}{*}{ Argamassas } & \multicolumn{4}{|c|}{ Massa dos materiais (g) } & \multirow{2}{*}{$\begin{array}{c}\text { Relação } \\
\text { água/sólidos }{ }^{1} \\
(\mathrm{~g} / \mathrm{g})\end{array}$} & \multirow{2}{*}{$\begin{array}{c}\text { Relação } \\
\text { CH/adição } \\
(\mathrm{g} / \mathrm{g})\end{array}$} \\
\hline & & $\begin{array}{c}\text { Hidróxido } \\
\text { de cálcio }\end{array}$ & $\begin{array}{c}\text { Areia } \\
\text { normal }\end{array}$ & $\begin{array}{c}\text { Adição } \\
\text { mineral }\end{array}$ & Água & & \\
\hline \multirow{3}{*}{$\begin{array}{l}\text { Adições } \\
\text { ativas }\end{array}$} & Cinza de casca de arroz & \multirow{5}{*}{104,0} & \multirow{5}{*}{936,0} & 196,9 & 200,0 & 0,66 & 0,53 \\
\hline & Sílica ativa & & & 202,4 & 340,0 & 1,11 & 0,51 \\
\hline & Metacaulim & & & 232,1 & 270,0 & 0,80 & 0,45 \\
\hline \multirow{2}{*}{$\begin{array}{l}\text { Adições } \\
\text { inertes }\end{array}$} & Fíler calcário & & & 250,7 & 180,0 & 0,51 & 0,41 \\
\hline & Fíler quartzoso & & & 241,4 & 200,0 & 0,58 & 0,43 \\
\hline
\end{tabular}

Nota: ${ }^{1}$ Relação água/sólidos: quociente entre a massa de água e a soma das massas de hidróxido de cálcio e adição mineral contidas na argamassa - água/(hidróxido de cálcio + adição mineral); e ${ }^{2}$ Relação hidróxido de cálcio/adição: quociente entre as massas de hidróxido de cálcio e adição mineral contidas na argamassa. 
As amostras das diferentes pastas com cal hidratada, aos 7 dias de idade, foram retiradas da estufa a $55{ }^{\circ} \mathrm{C}$, fragmentadas em pedaços com dimensão máxima de 5,0 mm (aproximadamente), acondicionadas em recipientes poliméricos com tampa e congeladas/estocadas em freezer a $-30{ }^{\circ} \mathrm{C}$, para paralisar as reações de hidratação.

$\mathrm{Na}$ sequência, alguns fragmentos das amostras (volume necessário para a realização da difratometria de raios $\mathrm{X}$ ) foram liofilizados em Liofilizador Terroni LS 3000, para que a água livre fosse sublimada, restando nas amostras a água quimicamente combinada e parte da água adsorvida na estrutura dos compostos hidratados formados.

As amostras liofilizadas foram finamente moídas em almofariz cerâmico com pistilo, acondicionadas em Eppendorf ( $2 \mathrm{~mL}$ ) e estocadas em dessecador com sílica gel até a realização da difratometria de raios $\mathrm{X}$.

O preparo das amostras para a coleta dos difratogramas foi realizado pela prensagem manual no porta-amostra, seguido de exposição aos raios $\mathrm{X}$ no equipamento Rigaku Ultima IV X-Ray Diffractometer. A mensuração foi realizada entre $5^{\circ}$ e $75^{\circ} 2 \theta$, com passo angular de $0,02^{\circ} 2 \theta$ e tempo por passo de $1 \mathrm{~s}$. A análise utilizou tubo com ânodo de cobre, $40 \mathrm{kV} / 30 \mathrm{~mA}$ e fenda divergente de $1^{\circ}$.

A interpretação dos difratogramas foi realizada por meio do software X'Pert HighScore, da PANalytical, utilizando a base de dados do International Centre for Diffraction Data (ICCD).

\section{Resultados e discussões}

O potencial reativo das adições minerais, obtido pelo método indireto normatizado, está baseado na determinação da carga de ruptura à compressão de corpos de prova moldados com proporção de mistura volumétrica dos materiais particulados fixa e com volume de água variável, já que as argamassas no estado fresco devem apresentar um índice de consistência preestabelecido. As condições impositivas preconizadas pela norma NBR 5751 (ABNT, 2012b) interferem diretamente no valor da resistência à compressão, pois, ao manter o volume de particulados constante e variar o volume de água de mistura em função das particularidades físico-químicas da adição mineral avaliada, há interferência na porosidade inicial do sistema (teórica), o que influencia a capacidade portante da argamassa no estado endurecido. Dessa forma, os resultados de resistência à compressão obtidos para diferentes adições minerais não podem ser comparados, mas relacionados a um valor mínimo de resistência à compressão.

As considerações apresentadas evidenciam que a metodologia indireta de avaliação do potencial reativo (ABNT, 2012b) das adições minerais não contemplam/restringem fatores intervenientes importantes que exercem influência no IAP baseado no ensaio de ruptura à compressão. Cabe ressaltar que a metodologia citada não distingue os efeitos físico e químico das adições minerais, e, portanto, o resultado experimental expressa a influência conjunta das partículas no sistema avaliado. A Figura 2 apresenta os resultados de resistência à compressão das argamassas contendo as diferentes adições minerais estudadas.

Figura 2 - Resistência à compressão de argamassas com hidróxido de cálcio e diferentes adições minerais, conforme preconiza a NBR 5751 (ABNT, 2012b)

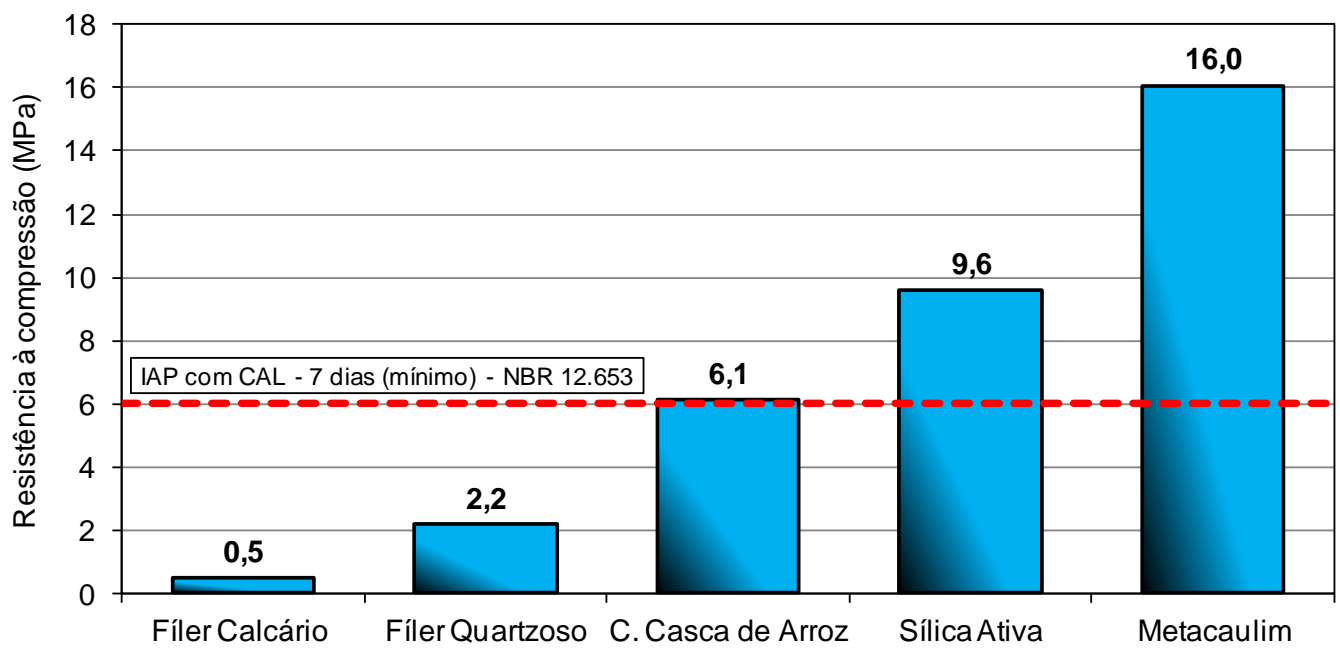


As argamassas com adições minerais inertes, ou seja, o fíler calcário e o fíler quartzoso, apresentaram resistência à compressão aquém do mínimo de 6,0 MPa, preconizado pela NBR 12653 (ABNT, 2012d). De fato, esse comportamento previsível evidencia que não há atividade química significativa entre o hidróxido de cálcio e os inertes estudados, e, dessa forma, essas adições não são classificadas como pozolânicas. As argamassas contendo cinza de casca de arroz, sílica ativa ou metacaulim atingiram a resistência à compressão mínima preconizada pela NBR 12653 (ABNT, 2012d). Portanto, com base na metodologia de avaliação da atividade pozolânica proposta pela NBR 5751 (ABNT, 2012b), são classificadas como materiais pozolânicos passíveis de incorporação na composição de cimento Portland composto ou pozolânico. A avaliação da cinza de casca de arroz resultou em resistência à compressão média de $6,1 \mathrm{MPa}$, valor muito próximo do mínimo estabelecido por norma, ou seja, uma pequena variação nos resultados experimentais poderia propiciar redução no valor médio de resistência à compressão, inviabilizando sua classificação como pozolana, apesar de ser citado na literatura, como em Hoppe Filho et al. (2012), que esse material apresenta atividade pozolânica mesmo em situação em que não há controle de temperatura de queima.

A argamassa contendo metacaulim apresentou a maior resistência à compressão entre as adições minerais ativas estudadas, atingindo $16,0 \mathrm{MPa}$ aos 7 dias de idade, seguido da argamassa com sílica ativa, com resistência à compressão média de 9,6 $\mathrm{MPa}, \mathrm{e}$, por fim, a argamassa com cinza de casca de arroz. As diferentes relações água/sólidos utilizadas no amassamento das argamassas interferem na resistência à compressão e, nesse sentido, a argamassa com metacaulim tende a apresentar maior capacidade portante em comparação à argamassa contendo sílica ativa, já que demandou menor volume de água de mistura. A argamassa com cinza de casca de arroz demandou a menor quantidade de água de mistura, porém apresentou a menor resistência à compressão, indicando que a morfologia alveolar das partículas dessa adição e a microestrutura da matriz hidratada formada exercem maior influência na carga de ruptura à compressão do que o volume de água de amassamento.

Os difratogramas das pastas contendo adição mineral inerte, coletados após 7 dias de cura conforme as diretrizes da NBR 5751 (ABNT, 2012b), são apresentados na Figura 3.

Na Figura 3 a pasta moldada com fíler calcário apresenta picos característicos de calcita $\left(\mathrm{CaCO}_{3}\right)$, dolomita $\left(\mathrm{CaCO}_{3} \cdot \mathrm{MgCO}_{3}\right)$, quartzo $\left(\mathrm{SiO}_{2}\right)$ e brucita $\left(\mathrm{Mg}(\mathrm{OH})_{2}\right)$, oriundos da adição mineral, e picos da portlandita utilizada na composição da pasta. A identificação da brucita se deve à hidratação do óxido de magnésio presente no calcário durante o período de cura da pasta. $\mathrm{Na}$ pasta contendo fíler quartzoso (pó de quartzo) foram identificados, após 7 dias de cura, o quartzo e a portlandita. Não há evidências em ambas as pastas da formação de qualquer produto hidratado, comprovando assim que tais adições minerais são inertes, podendo ser utilizadas como material de enchimento em sistema cimentício, ou seja, para melhorar o empacotamento das partículas e propiciar pontos extras para a nucleação dos compostos hidratados formados.

Por outro lado, nas pastas contendo adições minerais ativas foram identificados compostos hidratados e halo amorfo característico de estrutura vítrea, além do consumo de portlandita por atividade pozolânica. A Figura 4 apresenta os difratogramas das diferentes pastas, com a identificação das fases cristalinas presentes nas adições minerais e os compostos hidratados formados.

$\mathrm{Na}$ pasta com cinza de casca de arroz foram identificados picos referentes à cristobalita $\left(\mathrm{SiO}_{2}\right)$, uma das formas polimórficas do dióxido de silício, indicando haver, além da estrutura vítrea da pozolana, uma estrutura cristalina metaestável. O halo amorfo destacado no difratograma indica que na idade de 7 dias a atividade pozolânica não consumiu totalmente a sílica amorfa e que, portanto, há potencial para que a reação tenha prosseguimento, desde que haja disponibilidade de cal e maior tempo de cura. A identificação de portlandita possibilita haver continuidade da reação química, interrompida pelo término do ensaio. Assim sendo, o período estabelecido pela norma, apesar da catalisação da reação pela cura térmica a $(55 \pm 2){ }^{\circ} \mathrm{C}$, não é suficiente para que a cinza de casca de arroz consuma totalmente a portlandita disponível, interferindo no resultado de carga de ruptura à compressão. Por fím, a identificação do silicato de cálcio hidratado (C-S$\mathrm{H})$, com relação cálcio/sílica de 1,5 , evidencia a formação de matriz hidratada, resultado da atividade pozolânica. 
Figura 3 - Difração de raios $X$ das pastas com adições minerais inertes, após 7 dias de cura, conforme recomendações da NBR 5751 (ABNT, 2012b)
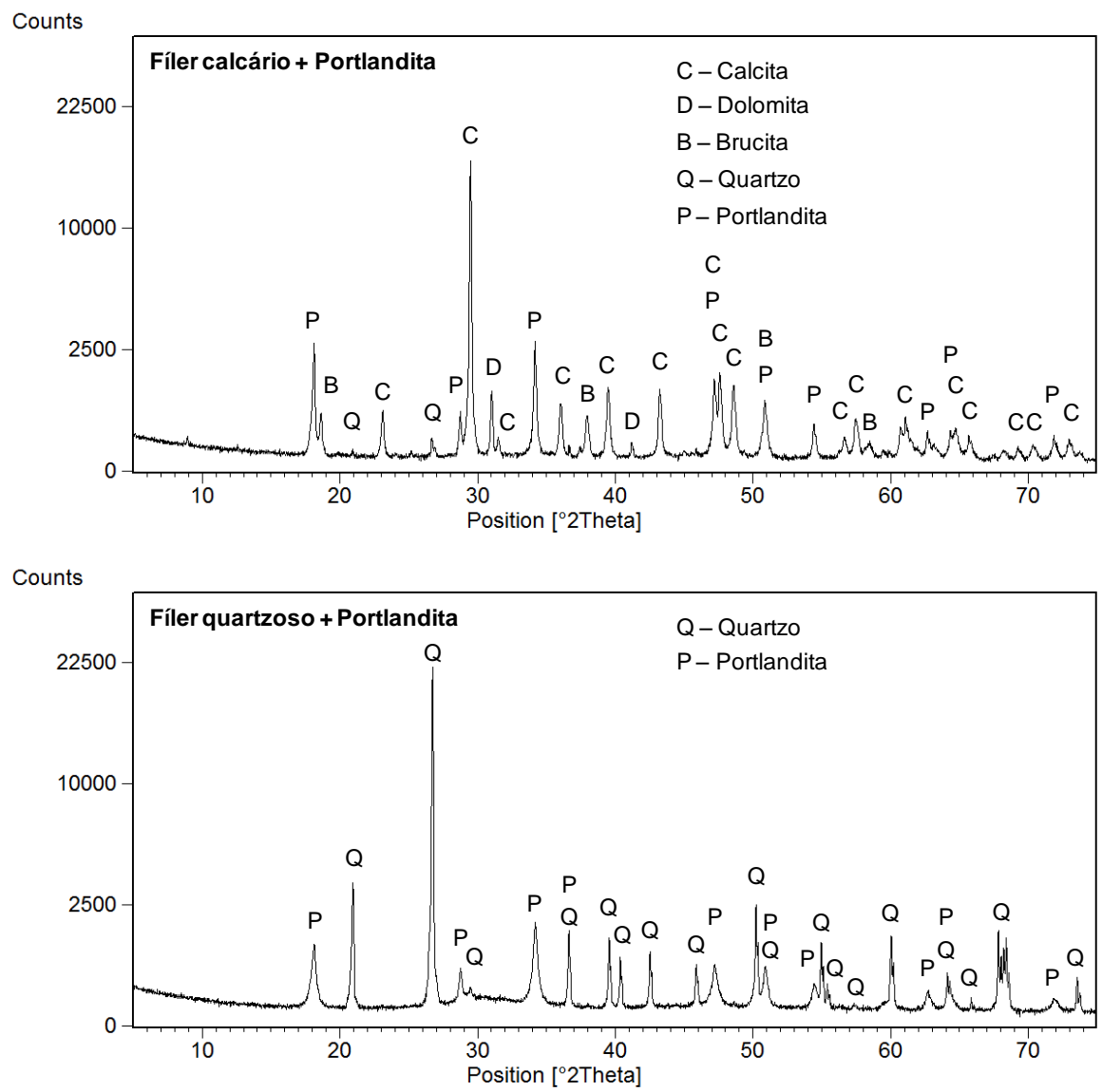

A pasta pozolânica com sílica ativa apresenta halo amorfo, indicando haver matriz vítrea remanescente, e picos característicos do C-S-H, com diferentes relações cálcio/sílica (variando entre 1,0 e 2,0). A portlandita foi totalmente consumida, e, dessa forma, não há presença de picos que a identifiquem no difratograma.

O metacaulim também consumiu totalmente a portlandita disponível, formando C-S-H e sílicoaluminato de cálcio hidratado sem que houvesse o esgotamento da matriz vítrea, identificada pela presença no halo amorfo no difratograma.

Os resultados da difração de raios $\mathrm{X}$ evidenciam que a determinação do IAP não considera parâmetros importantes que influenciam diretamente $o$ resultado de resistência à compressão dos sistemas que contêm adições minerais de alta reatividade. O principal parâmetro desconsiderado é a disponibilidade de portlandita durante o período de ensaio, ou seja, quando as reações pozolânicas são interrompidas, deve haver reserva alcalina; caso contrário, o potencial reativo das adições minerais no período preestabelecido não pode ser avaliado comparativamente em virtude da indisponibilidade de cal a ser fixada na formação dos compostos hidratados, o que interfere na carga de ruptura à compressão. 
Figura 4 - Difração de raios $X$ das pastas com adições minerais ativas após 7 dias de cura, conforme recomendações da NBR 5751 (ABNT, 2012b)
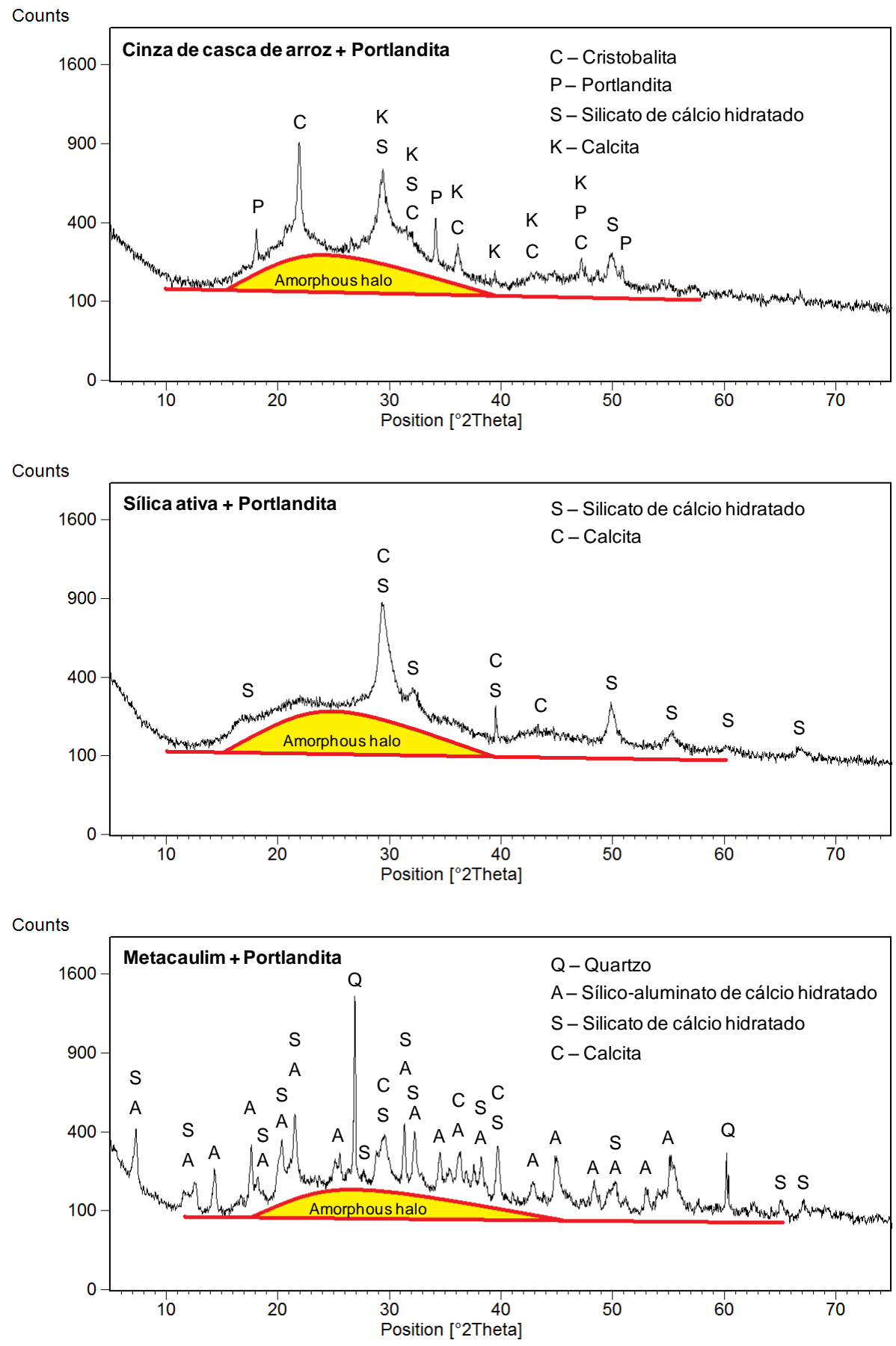

A Figura 5 apresenta em destaque o pico de maior intensidade da portlandita nos diferentes difratogramas, evidenciando seu esgotamento nos sistemas contendo sílica ativa ou metacaulim, com resquícios de teor remanescente na pasta com cinza de casca de arroz.

A presença de halo amorfo em todos os difratogramas significa que a atividade pozolânica foi interrompida sem que houvesse a total despolimerização da matriz vítrea (dependente do $\mathrm{pH}$ da solução aquosa), que, nesse caso, ocorreu em virtude do esgotamento da cal nos sistemas. Assim sendo, a disponibilidade de portlandita no sistema é imprescindível para que os outros fatores intervenientes sejam avaliados, entre eles a área específica das adições minerais e a cinética de reação em função da composição química da amostra ensaiada. 
Figura 5 - Teor de portlandita remanescente nos diferentes sistemas de cal com adições minerais após 7 dias de cura, conforme recomendações da NBR 5751 (ABNT, 2012b)

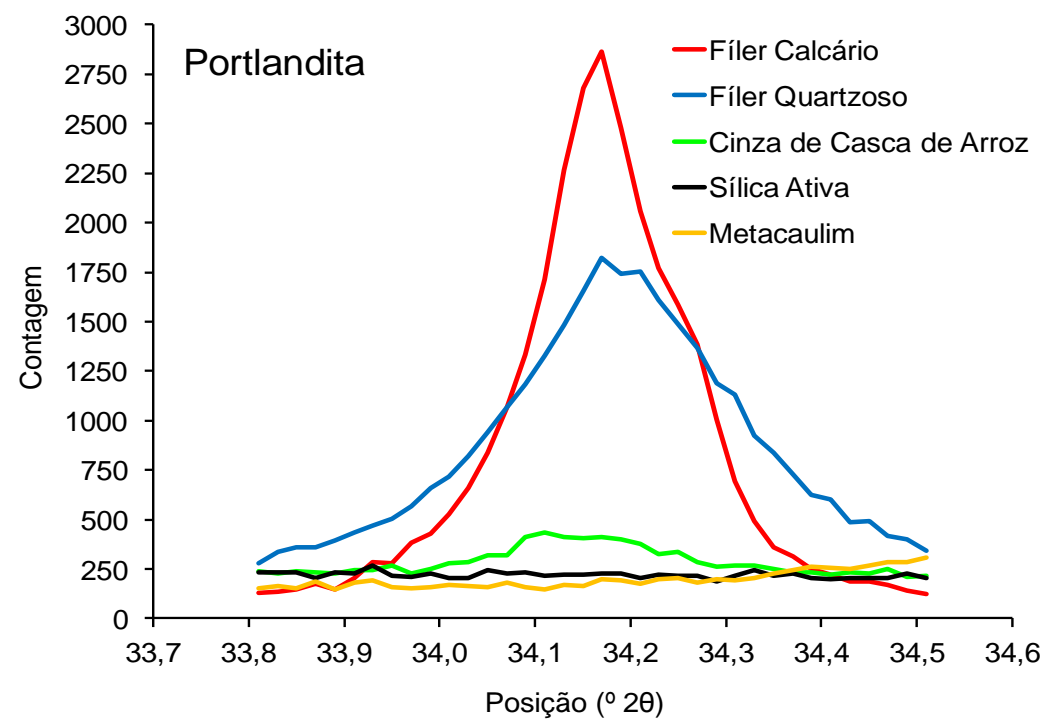

A importância da disponibilidade de cal pode ser observada com a publicação da norma NBR 15895 em 2010, a qual preconiza a proporção de $2,0 \mathrm{~g}$ de óxido de cálcio para $1,0 \mathrm{~g}$ de pozolana a ser ensaiada, o que resulta na relação $2,6 \mathrm{~g}$ de portlandita/grama de pozolana. $\mathrm{O}$ ensaio Chapelle modificado era até então realizado com a proporção de $1,0 \mathrm{~g}$ de óxido de cálcio para $1,0 \mathrm{~g}$ de pozolana, o que acarretava o consumo total da cal quando do ensaio de adições minerais de alta reatividade. Nesse sentido, a referida norma já contempla o ensaio de pozolanas altamente reativas sem que haja o esgotamento da cal no sistema, o que representa um avanço tecnológico no estudo da atividade pozolânica no que tange ao método direto de avaliação.

As adições minerais utilizadas neste estudo estavam submetidas a uma proporção média de $0,45 \mathrm{~g}$ de portlandita por unidade de massa de pozolana, que, apesar das condições distintas de ensaio em comparação ao ensaio Chapelle modificado, se mostrou insuficiente para atender à demanda de cal da atividade pozolânica, conforme os resultados da difratometria. Portanto, a proporção volumétrica dos materiais particulados preconizada na norma NBR 5751 (ABNT, 2012b) não é adequada para a determinação do IAP de superpozolanas.

\section{Conclusões}

Os resultados obtidos neste pesquisa propiciam as conclusões a seguir.

A metodologia proposta na norma NBR 5751 (ABNT, 2012b) não é adequada para a avaliação de pozolanas de alta reatividade, como a cinza de casca de arroz, o metacaulim e a sílica ativa, em virtude do esgotamento da reserva alcalina durante o período de ensaio.

O estudo de adições pozolânicas de alta reatividade requer a redução da relação volumétrica de adição/cal (2:1) para que haja reserva alcalina ao término do ensaio.

A resistência à compressão dos sistemas pozolânicos não está diretamente relacionada à reatividade das adições minerais, o que pode resultar em classificação errônea de determinada adição mineral.

O índice de consistência preestabelecido na norma interefere na demanda de água de amassamento e, consequentemente, na resistência à compressão da argamassa, o que impossibilita a simples comparação dos resultados de IAP. Portanto, há de se fixar o volume de água de mistura e utilizar aditivo dispersante para controlar a consistência da argamassa.

A NBR 5751 (ABNT, 2012b) não contempla parâmetros intervenientes importantes à atividade pozolânica, como a área específica BET, as características físico-químicas das pozolanas, o teor de amorfos e a taxa de reação ao longo do tempo em função da temperatura de cura, os quais interferem na capacidade portante da argamassa no estado endurecido. 


\section{Referências}

ABD-EL.AZIZ, M. A.; ABD.EL.ALEEM, S.; HEIKAL, M. Physico-Chemical and Mechanical Characteristics of Pozzolanic Cement Pastes and Mortars Hydrated at Different Curing Temperatures. Construction and Building Materials, v. 26, p. 310-316, 2012.

ASSOCIAÇÃO BRASILEIRA DE NORMAS TÉCNICAS. NBR 5751: materiais pozolânicos: determinação de atividade pozolânica: índice de atividade pozolânica com cal. Rio de Janeiro, 2012b.

\section{ASSOCIAÇÃO BRASILEIRA DE NORMAS} TÉCNICAS. NBR 5752: materiais pozolânicos: determinação de atividade pozolânica com cimento Portland: índice de atividade pozolânica com cimento. Rio de Janeiro, 2012a.

ASSOCIAÇÃO BRASILEIRA DE NORMAS TÉCNICAS. NBR 15895: materiais pozolânicos: determinação do teor de hidróxido de cálcio fixado: método Chapelle modificado. Rio de Janeiro, 2010.

\section{ASSOCIAÇÃO BRASILEIRA DE NORMAS}

TÉCNICAS. NBR 7214: areia normal para ensaio de cimento. Rio de Janeiro, 2012c.

\section{ASSOCIAÇÃO BRASILEIRA DE NORMAS}

TÉCNICAS. NBR 12653: materiais pozolânicos: requisitos. Rio de Janeiro, 2012d.

BARATA, M. S.; ANGÉLICA, R. S. Atividade Pozolânica dos Resíduos Cauliníticos das Indústrias de Mineração de Caulim da Amazônia. Revista Matéria, v. 16, n. 3, p. 795-810, 2011.

CERVO, T. C. Influência da Finura e da Porcentagem de Adição de Pozolanas na Durabilidade do Concreto. Santa Maria, 2001. Dissertação (Mestrado em Engenharia Civil) Escola de Engenharia, Universidade Federal de Santa Maria, Santa Maria, 2001.

CHAKCHOUK, A. et al. Formulation of Blended Cement: effect of process variables on clay pozzolanic activity. Construction and Building Materials, v. 23, n. 3, p. 1365-1373, 2009.

CORDEIRO, G. C. et al. Pozzolanic Activity and Filler Effect of Sugar Cane Bagasse Ash in Portland Cement and Lime Mortars. Cement \& Concrete Composites, v. 30, n. 5, p. 410-418, 2008.

CORDEIRO, G. C. et al. Influence of Particle Size and Specific Surface Area on the Pozzolanic Activity of Residual Rice Husk Ash. Cement \& Concrete Composites, v. 33, n. 5, p. 529-534, 2011.
DONATELLO, S.; TYER, M.; CHEESEMAN, C. R. Comparison of Test Methods to Assess Pozzolanic Activity. Cement \& Concrete Composites, v. 32, n. 2, p. 121-127, 2010.

FRÍAS, M.; VILLAR COCIÑA, E.;

SAVASTANO JUNIOR, H. Brazilian Sugar Cane Bagasse Ashes From the Cogeneration Industry as Active Pozzolans For Cement Manufacture.

Cement \& Concrete Composites, v. 33, n. 4, p. 490-496, 2011

GAVA, G. P.; PRUDÊNCIO JUNIOR., L. R. Pozzolanic Activity Tests as a Measure of Pozzolans' Performance: part 1. Magazine of Concrete Research, v. 10, p. 735-741, 2007.

GOBBI, A.; GROENWOLD, J. A.; MEDEIROS, M. H. F. de. Cinza de Bagaço de Cana-de-Açúcar: contribuição para a sustentabilidade dos materiais de reparo. In: CONGRESSO INTERNACIONAL SOBRE PATOLOGIAS E REABILITAÇÃO DE ESTRUTURAS, 6., 2010, Córdoba. Anais... Córdoba, 2010.

HEEDE, P. V.; BELIE, N. A Service Life Based Global Warming Potential For High-Volume Fly Asc Concrete Exposed to Carbonations.

Construction and Building Materials, v. 55, p. 183-193, 2014.

HODHOD, O. A.; SALAMA, G. Simulating USB4908 by ANN Modeling to Analyse the Effect of Mineral Admixture With Ordinary and Pozzolanic Cements on the Sulfate Resistance of Concrete. Housing and Building National Research Center, v. 9, p. 109-117, 2013.

HOPPE FILHO, J. Efeitos da Adição de cal Hidratada Sobre a Permeabilidade ao Oxigênio e Absorção Capilar de Concreto Com Altos Teores de Adições Minerais. Dissertação (Mestrado em Engenharia Civil) - Escola de Engenharia, Universidade Federal de Santa Maria, Santa Maria, 2002.

HOPPE FILHO, J. et al. Atividade Pozolânica de Cinza de Casca de Arroz Residual Com Diferentes Tamanhos de Partículas. In: CONGRESSO BRASILEIRO DO CONCRETO, 54., Maceió, 2012. Anais... Maceió, 2012.

HOPPE FILHO, J. et al. Potencial de Mitigação do Ataque Por Sulfatos Provocado Por Adições Minerais. In: CONGRESSO BRASILEIRO DE PATOLOGIA DAS CONSTRUÇÕES, Foz do Iguaçu, 2014. Anais... Foz do Iguaçu, 2014.

HOPPE FILHO, J. et al. High-Volume Fly Ash Concrete With and Without Hydrated Lime: chloride diffusion coefficient from accelerated test. Journal of Materials in Civil Engineering, v. 25, n. 3, p. 411-418, 2013. 
ISAIA, G. C. Efeitos de Misturas Binárias e Ternárias de Pozolanas em Concreto de Alto Desempenho: um estudo de durabilidade com vistas à corrosão da armadura. São Paulo, 1995. Tese ( Doutorado em Engenharia Civil - Escola de Engenharia, Universidade de São Paulo, São Paulo, 1995.

ISAIA, G. C.; GASTALDINI, A. L. G. Concrete Sustainability With Very High Amount of Fly Ash and Slag. Revista IBRACON de Estruturas e Materiais, v. 2, p. 244-253, 2009.

ISAIA, G. C.; FURQUIM, P.; GASTALDINI, A. L. A Statistical Approach of Binary and Ternary Concrete Mixtures With Mineral Additions.

Construction \& Building Materials, v. 36, p. 597-603, 2012.

KANNING, R. C. et al. Banana Leaves Ashes as Pozzolan For Concrete and Mortar of Portland Cement. Construction \& Building Materials, v. 54, p. 460-465, 2014.

LEE, G. et al. Effects of Crushed Glass Cullet Sizes, Casting Methods and Pozzolanic Materials on ASR of Concrete Blocks. Construction and Building Materials, v. 25, n. 5, p. 2611-2618, 2011.

MARQUES, P. F.; CHASTRE, C.; NUNES, A. Carbonation Service Life Modelling of RC Structures For Concrete With Portland and Blended Cements. Cement and Concrete Composites, v. 37, n. 3, p. 171-184, 2013.
MEDEIROS, M. H. F. et al. High Strength Reinforced Concrete With Metakaolin and Silica Fume in Marine Environment: an experimental work. Hormigón y Acero, v. 63, p. 57-66, 2012.

MEHTA, P. K.; MONTEIRO, P. Concreto, Microestrutura, Propriedades e Materiais. São Paulo, Brasil: IBRACON, 2014.

PACHECO-TORGAL, F.; JALALI, S. Sulphuric Acid Resistance of Plain, Polymer Modified, and Fly Ash Cement Concretes. Construction and Building Materials, v. 23, p. 3485-3491, 2009.

VILLAR-COCIÑA, E. et al. Pozzolanic Behavior of Bamboo Leaf Ash: characterization and determination of the kinetic parameters. Cement and Concrete Composites, v. 33, n. 1, p. 68-73, 2011.

ZERBINO, R.; GIACCIO, G.; ISAIA, G. C. Concrete Incorporating Rice-Husk Ash Without Processing. Construction and Building Materials, v. 25, n. 1, p. 371-378, 2011.

ZERBINO, R. et al. Alkali-Silica Reaction in Mortars and Concretes Incorporating Natural Rice Husk Ash. Construction and Building Materials, v. 36, p. 796-806, 2012.

\footnotetext{
Marcelo Henrique Farias de Medeiros

Departamento de Construção Civil | Universidade Federal do Paraná | Av. Cel. Francisco H. Dos Santos, s/n, Centro Politécnico | Curitiba - PR - Brasil | CEP 81530-900 | Tel.: (41) 3361-3438 | E-mail: medeiros.ufpr@gmail.com

Juarez Hoppe Filho

Centro das Ciências Exatas e das Tecnologias | Universidade Federal do Oeste da Bahia | Rua Professor José Seabra de Lemos, 316 Recanto dos Pássaros | Barreiras - BA - Brasil | CEP 47808-021 | Tel.: (77) 3614-3145 | E-mail: juarez.hoppe@gmail.com

Andressa Gobbi

Departamento de Construção Civil | Universidade Federal do Paraná | E-mail: andressagobbi@yahoo.com.br

Eduardo Pereira

Departamento de Engenharia Civil | Universidade Estadual de Ponta Grossa | Av. Carlos Cavalcanti, 4748, Uvaranas | Ponta Grossa - PR Brasil | CEP 84030-900 | Tel.: (42) 3220-3077 | E-mail: eduardopereira@uepg.br
}

Revista Ambiente Construído

Associação Nacional de Tecnologia do Ambiente Construído

Av. Osvaldo Aranha, $99-3^{\circ}$ andar, Centro

Porto Alegre - RS - Brasil

CEP $90035-190$

Telefone: +55 (51) 3308-4084

Fax: +55 (51) 3308-4054

www.seer.ufrgs.br/ambienteconstruido

E-mail: ambienteconstruido@ufrgs.br 